\title{
Surgical and Obstetric Outcomes in Adults with Sickle Cell Disease
}

\author{
Soheir Adam, MDa, Jude Jonassaint, RN ${ }^{\mathrm{a}}$, Hillary Kruger, BS ${ }^{\mathrm{a}}$, Melanie Kail, MS ${ }^{\mathrm{a}}$, Eugene \\ P. Orringer, MD $^{\mathrm{b}}$, James R. Eckman, $\mathbf{M D}^{\mathrm{c}}$, Allison Ashley-Koch, $\mathrm{PhD}^{\mathrm{a}}$, Marilyn J. Telen, \\ $M^{a}$, and Laura M. De Castro, MDa \\ aDepartment of Medicine, Duke University, Durham, North Carolina \\ ${ }^{b}$ Department of Medicine, University of North Carolina, Chapel Hill \\ 'Department of Medicine, Emory University, Atlanta, Ga
}

\begin{abstract}
BACKGROUND—Sickle cell disease patients are more likely than the general population to undergo surgery and usually do so at a younger age. Female sickle cell disease patients also have special gynecological and obstetric issues related to their disease.

METHODS-We collected data through standardized clinical report forms, patient interviews, and medical records from 509 adult sickle cell disease patients. Logistic regression was used to estimate the association between multiple variables and each of the surgery types. We also determined the prevalence and outcomes of pregnancy in 284 women with sickle cell disease in this population.
\end{abstract}

\begin{abstract}
RESULTS-Almost 50\% of patients aged 18-27 years had had a cholecystectomy. Mean corpuscular hemoglobin, total bilirubin, and lactate dehydrogenase were significantly higher in the postcholecystectomy group; $9.5 \%$ of 504 individuals had undergone splenectomy. Hematocrit, body mass index, and red blood cell count were significantly higher in the postsplenectomy group. Hip replacement had been performed in $9.2 \%$ of individuals, with the prevalence increasing as early as the fourth decade and continuing to increase through the sixth decade of life. A history of pregnancy was present in 190 women (67\%). Of 410 pregnancies, only $53.9 \%$ resulted in live births, $16.6 \%$ were voluntarily terminated, and $29.5 \%$ were complicated by miscarriage, still birth, or ectopic implantation.
\end{abstract}

CONCLUSIONS-Sickle cell disease continues to have a strong effect on the mean age for common surgeries and impacts pregnancy outcomes. We conclude that this population has a unique surgical and obstetric history that should be further studied to provide insight into potentially more effective preventive approaches to end-organ damage.

\section{Keywords}

Cholecystectomy; Pregnancy; Pregnancy complications; Sickle cell disease; Surgery

\footnotetext{
(C) 2008 Elsevier Inc. All rights reserved.
}

Requests for reprints should be addressed to Soheir Adam, MD, Duke Comprehensive Sickle Cell Center, Duke University, Box 3939, Durham, NC 27710. soheir.adam@duke.edu. 


\section{INTRODUCTION}

Sickle cell disease is an inherited hemoglobinopathy, resulting from a single nucleotide change in the gene encoding the $\beta$ chain of hemoglobin. The mutant $\beta$ globin chains ( $\mathrm{HbS})$ render the red cells more prone to hemolysis, due at least in part to polymerization of deoxyhemoglobin. In addition, $\mathrm{HbS}$ red cells contribute to the process of vasoocclusion in both large and small vessels. Adhesion of $\mathrm{HbS}$ cells results in endothelial damage and upregulation of adhesion molecules, which stimulates further red cell and leukocyte adhesion, as well as the release of various cytokines and proteolytic enzymes. This process ultimately leads to severe anemia and impaired tissue perfusion, resulting in a broad array of end-organ complications. Chronic hemolysis also results in pigment gallstone formation and cholelithiasis. Splenic sequestration and splenic pooling can be a major cause of morbidity and mortality in children with sickle cell disease and in adults with other sickle cell syndromes and often warrant splenectomy. Hypersplenism, splenic infarction, and increased transfusion requirements also might be indications for splenectomy. ${ }^{1}$ By age 35 years, about $50 \%$ of sickle cell disease patients have developed femoral head necrosis. Osteonecrosis of the femoral head results from infarction of the cancellous trabeculae. The femoral head is more commonly affected than other sites due to its weight-bearing function. ${ }^{2}$

Sickle cell disease patients are much more likely than the general population to undergo surgical procedures in their lifetime, ${ }^{3}$ and the age at which surgery is performed is younger than that of the general population. ${ }^{4,5}$ The Cooperative Study of Sickle Cell Disease reported the course and outcome of all surgical procedures performed for 717 sickle cell disease patients during the period from 1978 to $1988 .{ }^{6}$ For more than 2 decades, there have been no further reports on the prevalence of major surgeries in this population.

The aim of the present study was to determine the current prevalence of surgical procedures in an adult sickle cell disease population, in view of both improved medical care and the advent of hydroxyurea therapy for sickle cell disease. In addition, we examined patient characteristics associated with history of previous surgeries. We also analyzed the prevalence and outcomes of pregnancy in sickle cell disease.

\section{METHODS}

Over a period of 5 years (2002-2007), 509 unrelated adult patients were enrolled in the study after informed consent was obtained. There were 21 patients with $S \beta^{0}$ thalassemia and 488 patients who were homozygous for $\mathrm{HbS}$. The patient population came primarily from 3 major centers in the southeast United States: Duke University, Durham, NC; University of North Carolina, Chapel Hill, NC; and Emory University, Atlanta, GA. A small number of patients also were enrolled at East Carolina University, Greenville, NC, and the Carolinas Medical Center, Charlotte, NC. The patients enrolled at Duke University Medical Center, University of North Carolina, and Emory University represent more than half the HbSS patients followed regularly at these centers.

\section{Data Collection}

Medical history was obtained by both patient interviews and review of medical records, using standardized case report forms, and information was then entered into our Pedigene database. Other data collected included demographics, baseline hematology and chemistry laboratory values, vital signs, results of physical examination, body mass index (BMI), and current medications. 


\section{Statistical Analysis}

Contingency tables were used to provide descriptive frequencies of the surgical and obstetric outcomes. Logistic regression was used to identify statistically significant associations between surgical outcomes and possible predictor and related outcome variables. All analyses were conducted using SAS version 9.1 (PROC FREQ and PROC LOGISTIC; SAS Institute Inc., Cary, NC).

\section{RESULTS}

Among all surgeries studied, cholecystectomy was 5 times more common than other surgeries, while total hip replacement tended to be performed latest in life (Figure 1).

\section{Cholecystectomy}

Cholecystectomy was the most commonly reported surgery in this population (291/509, $57.17 \%$ ). Among patients $18-47$ years of age, $47.5 \%$ of subjects had already had a cholecystectomy; and $69 \%$ of those who were 47 years and older had undergone the procedure (Figure 1). The likelihood of having had a cholecystectomy increased with each year of age over 18 (odds ratio [OR] 1.028 per year). The mean corpuscular volume, total bilirubin, and lactate dehydrogenase were significantly higher for those who had had cholecystectomy than those without cholecystectomy $(P=.008, P=.008$, and $P=.006$ respectively, Table 1), although the reticulocyte count was not different between the 2 groups. The odds of having had a cholecystectomy increased for each femtoliter (fl) increase in mean corpuscular hemoglobin (OR 1.026). Also, the likelihood of having had a cholecystectomy increased with increases in serum bilirubin (OR 1.128 per $\mathrm{mg} / \mathrm{dL}$ increase). Furthermore, the odds of having had a cholecystectomy increased by 1.028 for each 50-unit increase in lactate dehydrogenase. Interestingly, there was no relationship between BMI or sex and cholecystectomy, despite the association of these variables with cholecystectomy in the general population.

\section{Splenectomy}

A history of surgical splenectomy was reported by 48 of 504 study subjects $(9.52 \%)$ for whom a response was recorded; 43 of 48 post-splenectomy subjects were ages 18-47 (Figure 2). The percentage of $\mathrm{S} \beta^{0}$ patients who had had splenectomy was $43 \%(9 / 21)$, while only $8.1 \%$ (39/483) of SS patients reported having had a splenectomy. The hematocrit was found to be significantly higher in the post-splenectomy group (26.3 vs 24.3$)(P=.017)$. Interestingly, individuals with a higher BMI also were more likely to have had surgical splenectomy $(P=.028$, Table 2$)$.

\section{Total Hip Replacement}

Hip replacement had been performed in 47/509 (9.23\%) individuals, and $85 \%$ of these reported having it by the age of 57 years (Figure 1). There was no significant difference between the BMI values in those with a history of total hip replacement and those with no history of total hip replacement ( $25.09 \pm 4.3$ and $23.8 \pm 4.9$, respectively, Table 3$)$. In addition, there were no differences in hematology or hemolysis-associated laboratory values between patients who had or had not undergone total hip replacement.

\section{Obstetrical History and Outcomes}

Of the 284 women included in this analysis, 190 subjects (66.9\%) reported a history of a total of 410 pregnancies, resulting in an average pregnancy rate of 2.16 for those who became pregnant at least once, but only 1.44 for all female subjects. The mean age at first delivery was 23.7 years. Of all reported pregnancies, 221 resulted in live births (53.9\%) and 
$121(29.51 \%)$ ended in miscarriages, stillbirths, or ectopic implantation. There were 68 $(16.59 \%)$ voluntary terminations (Table 4$)$.

\section{DISCUSSION}

Pigment gallstones originating from chronic hemolysis affect $20 \%$ of children and more than $80 \%$ of adults with sickle cell disease. ${ }^{7}$ Gallstones cause cholecystitis and recurrent attacks of abdominal pain. These frequent complications have historically made cholecystectomy the most common surgical procedure in sickle cell disease. In this study, we also found cholecystectomy to be the most commonly performed surgery. Almost one fifth of patients aged 18-27 years had undergone cholecystectomy. Recently, another group of investigators examined the 2004 Nationwide Inpatient Sample from the Healthcare Cost and Utilization Project and found that the mean age for cholecystectomy was $52.8 \pm 0.2$ years in the general population (Reed S, Chou SH, personal communication). Clearly, patients with sickle cell disease continue to undergo cholecystectomy at a far younger age than do other populations in the United States. Interestingly, the levels of bilirubin and lactate dehydrogenase were significantly higher in patients who had had cholecystectomy, suggesting that differences in hemolytic rate and possibly bilirubin metabolism affect the lifetime need for cholecystectomy, rather than just the age at cholecystectomy, as has been reported recently. ${ }^{8-10}$

Only a small number of our study population $(48 / 504,9.5 \%)$ had had their spleens surgically removed. Interestingly, splenectomy had occurred at a much higher rate in $\mathrm{Hb} \mathrm{S} \beta^{0}$ than in $\mathrm{Hb}$ SS patients (43\% in $\mathrm{S} \beta^{0}$ and $8 \%$ in SS). Therefore, the odds of having had a splenectomy were 9.17 times higher for individuals with $\mathrm{Hb} \mathrm{S} \beta^{0}$ compared with those with $\mathrm{Hb} \mathrm{SS}(P=$. 0001). Nationwide in 2004, the mean age of splenectomy was 17 years for sickle cell disease patients (Chou, Reed and colleagues, personal communication), as compared with 45 years in the healthy population. However, the nationwide data are likely to include patients with $\mathrm{Hb} \mathrm{SC}$ and $\mathrm{Hb} \mathrm{S} \beta^{+}$thalassemia as well, and such patients are more likely to undergo splenectomy at a later age than those with Hb SS. Nevertheless, we were surprised to find that the cumulative prevalence of splenectomy increased beyond age 27 years, even in a population limited to individuals with $\mathrm{Hb} \mathrm{SS}$ and $\mathrm{Hb} \mathrm{S} \beta^{0}$ thalassemia. This may reflect the possibility that use of splenectomy in sickle cell disease has decreased over time. The hematocrit also was significantly higher in those who had had splenectomy, despite the fact that in adulthood the vast majority of patients lack functional spleens; this appears to reflect the relative increase of splenectomy among the $\mathrm{Hb} \mathrm{S} \beta^{0}$ patients. Although $\mathrm{Hb}$ SS patients who were surgically splenectomized had a higher hematocrit than similar patients without splenectomy (25.43 vs 24.22), a greater difference was observed for $\mathrm{Hb} \mathrm{S} \beta^{0}$ patients (29.46 vs 26.58). Interestingly, splenectomized patients had a significantly higher BMI than nonsplenectomized subjects. This may be explained by the negative effect of hypersplenism and the hypercatabolic symptoms of an enlarged spleen on weight gain during childhood. In addition, $\mathrm{Hb} \mathrm{S} \beta^{0}$ patients were found to have higher body mass indices, thus skewing the $\mathrm{BMI}$ results between the 2 groups $\left(\mathrm{Hb} \mathrm{S} \beta^{0}\right.$ mean $\mathrm{BMI}=26.50, \mathrm{Hb} \mathrm{SS}$ mean $=23.91, P=$. 0403 controlling for age). Alternatively, individuals with higher hemoglobin levels may have increased risk of splenectomy and higher BMIs. Bone disease is one of the major complications of sickle cell disease. This includes bone infection, bone infarction, and osteonecrosis of the femoral and, less commonly, humeral heads. ${ }^{4}$

About half of the sickle cell disease population is expected to develop osteonecrosis by the age of 35 years. $^{2}$ The persistence of disabling pain that is unresponsive to conservative measures is usually considered an indication for arthroplasty. ${ }^{11}$ Hip arthroplasty is performed at a younger age in this population. ${ }^{12,13}$ While the mean age for hip replacement nationwide for all individuals is 69.8 years (Reed $\mathrm{S}$, Chou SH, personal communication), the 
prevalence of hip arthroplasty in sickle cell disease appears to increase significantly as early as the fourth and fifth decades of life (Figures 1,2). Furthermore, although it is well documented in the literature that obesity is a major risk factor for osteonecrosis in young adults, ${ }^{14-17}$ there was no correlation between BMI and hip replacement surgery in our study. However, this may be due to the small number of patients who had had hip surgery $(n=47)$, as well as to the wide variability in BMI values in our patient population. ${ }^{18}$

Overall, this study showed unique correlations between different types of surgery, patient age, and specific laboratory values. As shown in Figure 2, cholecystectomy was the most commonly reported surgery in all group ages. Interestingly, the prevalence of all 3 types of surgeries appeared to plateau as patients aged, as shown in Figure 1. Around $40 \%$ of patients below the age of 28 years had a history of cholecystectomy, and most cholecystectomies appear to have been performed by age 50 years in this population. On the other hand, splenectomies were largely performed before age 40 years. Total hip replacements were rarely performed in patients younger than 37 years and also were rarely performed in patients above the age of 57 years.

The average rate of pregnancy was found to be 1.44 among all sickle cell disease women included in the analysis and 2.15 among those who had been pregnant. In the Cooperative Study of Sickle Cell Disease, 320 pregnancies were reported among 155 women, for a similar pregnancy rate of 2.1. ${ }^{19}$ The mean age at delivery was comparable to that in the general population, for which the mean age at delivery of all pregnancies is $27.7 \pm 0.1$ years.

Female sickle cell disease patients are known to have an increased incidence of pregnancyrelated complications. The rate of preterm delivery before 36 weeks of gestation has been estimated to be $30 \%-50 \%$ in sickle cell disease, with the average gestational age at delivery being 34 weeks. ${ }^{20}$ Earlier studies also have shown that more than one third of pregnancies in women with sickle cell disease end in abortion, stillbirth, or neonatal death. ${ }^{19}$ In the report from the Cooperative Study of Sickle Cell Disease, $28.5 \%$ of pregnancies were terminated electively and $6.5 \%$ spontaneously. Among 200 live births reported, $20 \%$ of the newborns were of low birth weight. The reported rate of live births in the general African-American population was $67.4 / 1000$ in $2002 .{ }^{21}$ In our study, women opted for voluntary terminations in only $16.6 \%$ of pregnancies, a number lower than that observed in the Cooperative Study of Sickle Cell Disease. This observation might reflect the more optimistic attitude of both health care providers and patients about pregnancy in this population. However, miscarriages, stillbirths, and ectopic implantations occurred in $29.5 \%$, while only $53.9 \%$ of pregnancies resulted in live births. Available data indicate that around $65 \%$ of pregnancies in the United States result in live births. Thus, while the percentage of live births in our study is actually slightly lower than that reported in the Cooperative Study of Sickle Cell Disease, also it remains considerably lower than in the general American population.

We conclude, therefore, that as sickle cell disease patients live longer, the need for better medical and surgical care for this population increases. The surgical and obstetric data in adults with sickle cell disease in our study demonstrate little positive change since the Cooperative Study of Sickle Cell Disease report of data collected approximately 2 decades previously, despite the advent of hydroxyurea therapy. Future research should focus on developing preventive measures for sickle cell disease complications in order to slow organ damage and reduce the need for surgery, especially arthroplasty. New agents also need to be developed to reduce the rate of hemolysis and, as a consequence, the incidence of cholelithiasis, thus deferring cholecystectomy. Other preventive measures to minimize vasoocclusion and bone necrosis should be investigated in order to obviate the need for splenectomy and total hip replacement at relatively young ages in sickle cell disease patients. Ideally, genetic polymorphisms associated with certain clinical complications in 
sickle cell disease patients need to be identified, in order eventually to allow the adoption of individually tailored prophylaxis in this population. We hope that risk stratification and preemptive intervention will reduce the need for surgery and the risk of negative outcomes of pregnancy in sickle cell disease in the future.

\section{Acknowledgments}

This work was supported by grants R01 HL68959 and U10 HL083698 from the National Heart, Lung and Blood Institute, National Institutes of Health (NIH). LDC is the Sickle Cell Scholar for the Duke-UNC Comprehensive Sickle Cell Center (HL070769). SA is a visiting scholar and an Assistant Professor at King Abdul Aziz University, Jeddah, Saudi Arabia.

\section{References}

1. Emond AM, Venugopal S, Morais P, et al. Role of splenectomy in homozygous sickle cell disease in childhood. Lancet. 1984; 323(8368):88-91. [PubMed: 6140433]

2. Styles LA, Vichinsky EP. Core decompression in avascular necrosis of the hip in sickle-cell disease. Am J Hematol. 1996; 52(2):103-107. [PubMed: 8638629]

3. Buck J, Davies SC. Surgery in sickle cell disease. Hematol Oncol Clin North Am. 2005; 19(5):897902. [PubMed: 16214650]

4. Vichinsky EP, Neumayr LD, Haberkern C, et al. The perioperative complication rate of orthopedic surgery in sickle cell disease: report of the national sickle cell surgery study group. Am J Hematol. 1999; 62:129-138. [PubMed: 10539878]

5. Haberkern CM, Neumayr LD, Orringer EP, et al. Cholecystectomy in sickle cell anemia patients: perioperative outcome of 364 cases from the National Preoperative Transfusion Study. Blood. 1997; 89:1533-1542. [PubMed: 9057634]

6. Koshy MM, Weiner SSJ, Miller SST, et al. Surgery and anesthesia in sickle cell disease. Cooperative Study of Sickle Cell Diseases. Blood. 1995; 86(10):3676-3684. [PubMed: 7579333]

7. Duncan ND, Smith AI, Macdonald AH, Mitchell DIG. Biliary surgery in sickle cell disease: the Jamaican experience. J R Coll Surg Edinb. 2002; 47(1):414-417. [PubMed: 11878301]

8. Chaar V, Keclard L, Etienne-Julan M, et al. UGT1A1 polymorphism outweighs the modest effect of deletional $(-3.7 \mathrm{~kb})$ alpha-thalassemia on cholelithogenesis in sickle cell anemia. Am J Hematol. 2006; 81(5):377-379. [PubMed: 16628735]

9. Adekile A, Kutlar F, McKie K, et al. The influence of uridine diphosphate glucuronosyl transferase 1A promoter polymorphisms, beta-globin gene haplotype, co-inherited alpha-thalassemia trait and $\mathrm{Hb}$ F on steady-state serum bilirubin levels in sickle cell anemia. Eur J Haematol. 2005; 75(2):150 155. [PubMed: 16004608]

10. Fertrin KY, Melo MB, Assis AM, et al. UDP-glucuronosyltransferase 1 gene promoter polymorphism is associated with increased serum bilirubin levels and cholecystectomy in patients with sickle cell anemia. Clin Genet. 2003; 64(2):160-162. [PubMed: 12859413]

11. Jeong GK, Ruchelsman DE, Jazrawi LM, Jaffe WL. Total hip arthroplasty in sickle cell hemoglobinopathies. J Am Acad Orthop Surg. 2005; 13:208-217. [PubMed: 15938609]

12. Buck J, Casbard A, Llewelyn C, et al. Preoperative transfusion in sickle cell disease: a survey of practice in England. Eur J Haematol. 2005; 75(1):14-21. [PubMed: 15946305]

13. Firth PG, Head CA, Firth PG, Head CA. Sickle cell disease and anesthesia. Anesthesiology. 2004; 101(3):766-785. [PubMed: 15329603]

14. Harms S, Larson R, Sahmoun A, Beal J. Obesity increases the likelihood of total joint replacement surgery among younger adults. Int Orthop. 2007; 31(1):23-26. [PubMed: 16688455]

15. Wendelboe AM, Hegmann KT, Biggs JJ, et al. Relationships between body mass indices and surgical replacements of knee and hip joints. Am J Prev Med. 2003; 25(4):290-295. [PubMed: 14580629]

16. Marks R, Allegrante JP. Body mass indices in patients with disabling hip osteoarthritis. Arthritis Res. 2002; 4(2):112-116. [PubMed: 11879546] 
17. Horan F. Obesity and joint replacement. J Bone Joint Surg Br. 2006; 88(10):1269-1271. [PubMed: 17012412]

18. Pells JJ, Presnell KE, Edwards CL, et al. Moderate chronic pain, weight and dietary intake in African-American adult patients with sickle cell disease. J Natl Med Assoc. 2005; 97(12):16221629. [PubMed: 16396054]

19. Smith JJA, Espeland MM, Bellevue RR, et al. Pregnancy in sickle cell disease: experience of the Cooperative Study of Sickle Cell Disease. Obstet Gynecol. 1996; 87(2):199-204. [PubMed: 8559523]

20. Sun PM, Wilburn W, Raynor BD, Jamieson D. Sickle cell disease in pregnancy: twenty years of experience at Grady Memorial Hospital, Atlanta, Georgia. Am J Obstet Gynecol. 2001; 184(6): 1127-1130. [PubMed: 11349177]

21. Hamilton BE, Ventura SJ. Fertility and abortion rates in the United States, 1960-2002. Int J Androl. 2006; 29(1):34-45. [PubMed: 16466522] 


\section{CLINICAL SIGNIFICANCE}

- Sickle cell disease patients undergo cholecystectomy and hip replacement at ages much younger than the general population.

- The prevalence of all types of surgeries appears to plateau as patients age.

- The cumulative prevalence of splenectomy increased beyond the age of 27 years in $\mathrm{Hb} \mathrm{SS}$ and $\mathrm{S} \beta^{0}$ disease.

- The live birth rate for mothers with sickle cell disease remains considerably lower than for the general African-American population. 


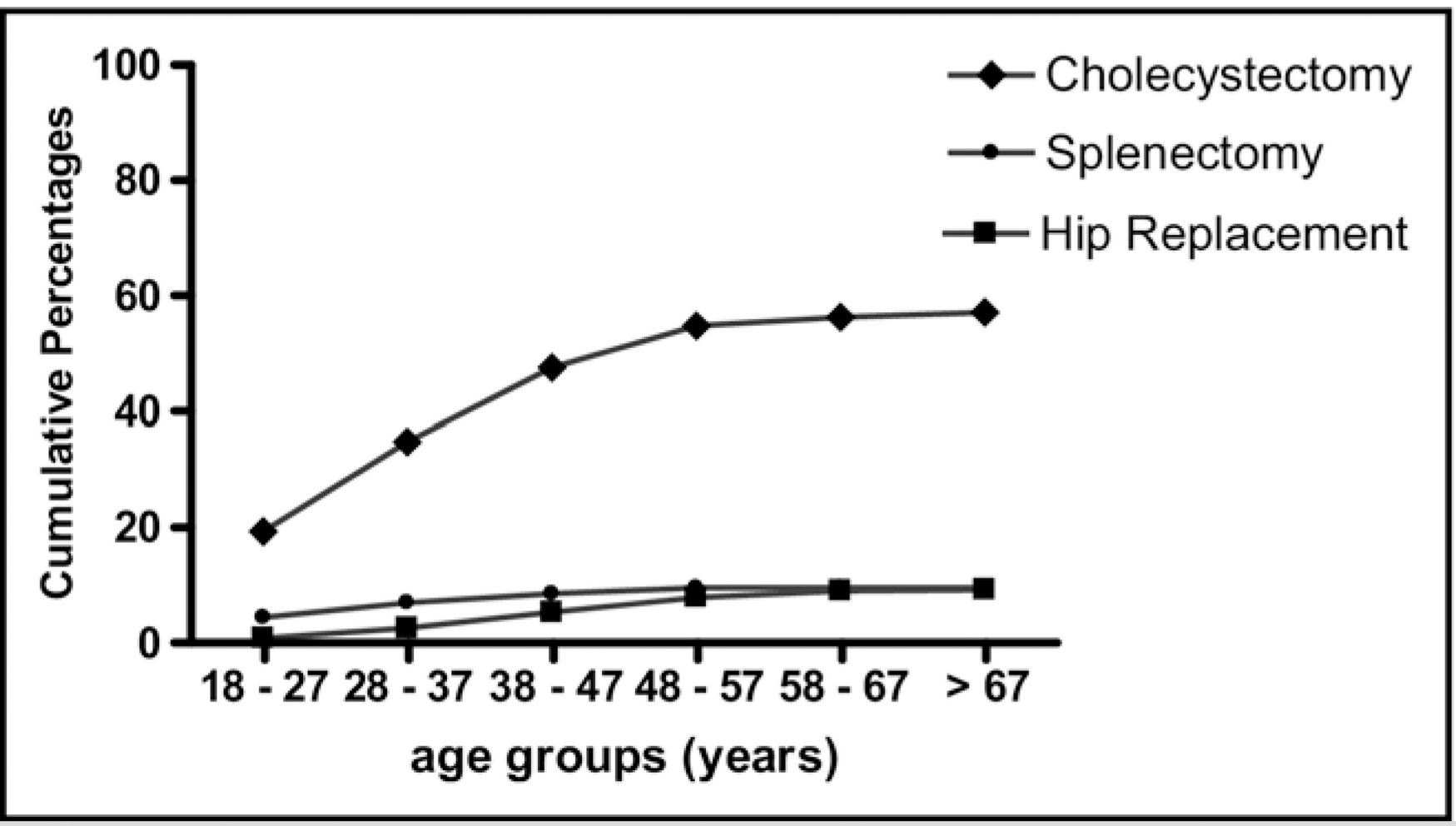

Figure 1.

Cumulative prevalence of surgical histories by age. The prevalence of cholecystectomy, splenectomy, and total hip replacement is shown. The frequency of all 3 types of surgeries appeared to plateau as patients aged. 


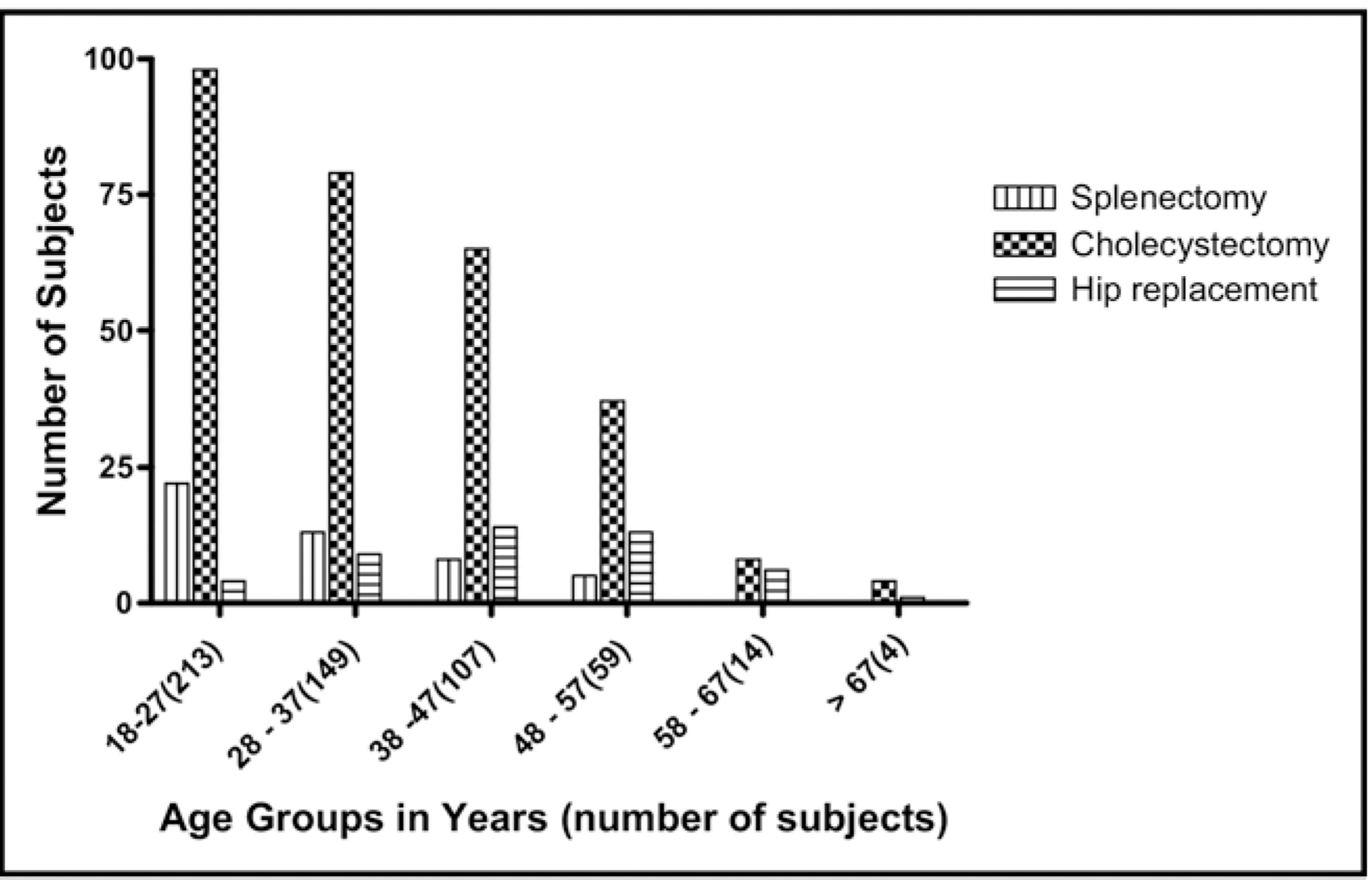

Figure 2.

Number of surgeries performed in each age group. The numbers of individuals who had had surgery in different age groups is compared. While a history of cholecystectomy is far more common than history of other surgeries in all groups, above age 38 years, a history of total hip replacement is more common than a history of splenectomy. 
Table 1

Correlation of Clinical and Laboratory Variables with Prevalence of Cholecystectomy

\begin{tabular}{|c|c|c|c|c|}
\hline Variable & Cholecystectomy & No Cholecystectomy & $P$ Value* & OR $(\mathbf{C I})^{\dagger}$ \\
\hline Sex ( $\%$ female $)$ & 59.1 & 49.5 & .081 & \\
\hline $\mathrm{Hb}(\mathrm{g} / \mathrm{dL})$ & $8.28 \pm 1.45$ & $8.44 \pm 1.52$ & .466 & \\
\hline Hct & $24.25 \pm 4.50$ & $24.67 \pm 4.53$ & .573 & \\
\hline $\mathrm{MCV}(\mathrm{fl})$ & $91.59 \pm 12.13$ & $88.04 \pm 10.40$ & .008 & $1.026(1.007-1.046)$ \\
\hline Abs. retic. count $\left(\times 10^{3} / \mu \mathrm{L}\right)$ & $298.34 \pm 131.70$ & $302.30 \pm 134.16$ & .983 & \\
\hline T. bilirubin (mg/dL) & $3.54 \pm 3.17$ & $2.93 \pm 2.04$ & .005 & $1.128(1.037-1.226)$ \\
\hline $\mathrm{LDH}(\mathrm{U} / \mathrm{L})^{\dagger}$ & $896.84 \pm 572.07$ & $742.82 \pm 489.97$ & .006 & $1.028(1.008-1.048)$ \\
\hline BMI & $23.93 \pm 4.85$ & 23.894 .93 & 642 & \\
\hline
\end{tabular}

$\mathrm{OR}=$ odds ratio $; \mathrm{CI}=$ confidence interval $\mathrm{Hb}=$ hemoglobin $; \mathrm{Hct}=$ hematocrit $; \mathrm{MCV}=$ mean corpuscular hemoglobin $;$ Abs. retic . count $=$ absolute reticulocyte count; $\mathrm{T}$. bilirubin $=$ total bilirubin; $\mathrm{LDH}=$ lactate dehydrogenase; $\mathrm{BMI}=$ body mass index.

* All $P$ values were obtained after controlling for age.

${ }^{\dagger}$ OR: per unit of measure.

* Odds ratio per 50 U/L LDH change. 
Table 2

Correlation of Clinical and Laboratory Variables with Prevalence of Splenectomy

\begin{tabular}{lcccc}
\hline Variable & Splenectomy & No Splenectomy & $\boldsymbol{P}$ Value & OR $(\mathbf{C I})^{\dagger}$ \\
\hline Sex $(\%$ female $)$ & $58.3 \%$ & $55.0 \%$ & .205 & \\
$\mathrm{RBC}\left(\times 10^{9} / \mathrm{L}\right)$ & $3.07 \pm 0.9$ & $2.72 \pm 0.6$ & .004 & $2.025(1.259-3.257)$ \\
$\mathrm{Hb}(\mathrm{g} / \mathrm{dL})^{\dagger}$ & $8.69 \pm 1.9$ & $8.32 \pm 1.4$ & .180 & \\
$\mathrm{Hct}^{*}$ & $26.31 \pm 5.6$ & $24.27 \pm 4.4$ & .017 & $1.096(1.017-1.182)$ \\
$\mathrm{MCV}(\mathrm{fl})$ & $87.12 \pm 12.0$ & $90.37 \pm 11.5$ & .122 & \\
$\mathrm{Abs}$. retic. count $\left(\times 10^{3} / \mu \mathrm{L}\right)$ & $280.14 \pm 101.8$ & $301.43 \pm 135.2$ & .368 & \\
T. bilirubin $(\mathrm{mg} / \mathrm{dL})$ & $2.60 \pm 1.9$ & $3.31 \pm 2.8$ & .085 & \\
LDH $(\mathrm{U} / \mathrm{L})$ & $912.30 \pm 510.8$ & $824.12 \pm 547.9$ & .334 & \\
$\mathrm{BMI}$ & $25.50 \pm 5.6$ & $23.75 \pm 4.8$ & .028 & $1.077(1.008-1.151)$ \\
\hline
\end{tabular}

$\mathrm{CI}=$ confidence interval $\mathrm{RBC}=$ red blood cell count $\mathrm{Hb}=$ hemoglobin; Hct = hematocrit $\mathrm{MCV}=$ mean corpuscular hemoglobin; Abs. Retic . Count $=$ absolute reticulocyte count; $\mathrm{T}$. bilirubin $=$ total bilirubin $; \mathrm{LDH}=$ lactate dehydrogenase BMI = body mass index; OR = odds ratio.

* All $P$ values were obtained after controlling for age.

${ }^{\dagger}$ OR: per unit of measure.

${ }^{\ddagger} \mathrm{Hb}$ SS only. 
Table 3

Correlation of Clinical and Laboratory Variables with Prevalence of Total Hip Replacement (THR) Surgery

\begin{tabular}{lccc}
\hline Variable & THR & No THR & P Value \\
\hline Sex $(\%$ female) & $57.4 \%$ & $55.2 \%$ & .452 \\
$\mathrm{Hb}(\mathrm{g} / \mathrm{dL})$ & $8.49 \pm 1.5$ & $8.33 \pm 1.5$ & .109 \\
$\mathrm{Hct}$ & $24.91 \pm 4.6$ & $24.39 \pm 4.5$ & .146 \\
$\mathrm{MCV}(\mathrm{fl})$ & $91.25 \pm 9.5$ & $89.99 \pm 11.7$ & .933 \\
Abs. Retic. Count $\left(\times 10^{3} / \mu \mathrm{L}\right)$ & $306.39 \pm 193.8$ & $298.21 \pm 125.4$ & .323 \\
T. bilirubin $(\mathrm{mg} / \mathrm{dL})$ & $2.44 \pm 1.6$ & $3.55 \pm 2.8$ & .158 \\
LDH $(\mathrm{U} / \mathrm{L})$ & $789.62 \pm 454.2$ & $834.60 \pm 550.7$ & .464 \\
BMI & $25.09 \pm 4.3$ & $23.82 \pm 4.9$ & .562 \\
\hline
\end{tabular}

$\mathrm{Hb}=$ hemoglobin Hct = hematocrit $\mathrm{MCV}=$ mean corpuscular hemoglobin; Abs. Retic. Count = absolute reticulocyte count; $\mathrm{T}$. bilirubin = total bilirubin; $\mathrm{LDH}=$ lactate dehydrogenase; $\mathrm{BMI}=$ body mass index; $\mathrm{OR}=$ odds ratio; $\mathrm{CI}=$ confidence interval.

All $P$ values were obtained after controlling for age. 